\title{
Erratum zu: Digitalisierung öffentlicher Dienstleistungen: Herausforderungen und Erfolgsfaktoren der OZG-Umsetzung in der Kommunalverwaltung
}

\author{
Sebastian Halsbenning
}

Online publiziert: 12. Januar 2022

(C) Springer Fachmedien Wiesbaden GmbH, ein Teil von Springer Nature 2022

\section{Erratum zu:}

\section{HMD 2021}

https://doi.org/10.1365/s40702-021-00765-5

Der Artikel „Digitalisierung öffentlicher Dienstleistungen:“ von Sebastian Halsbenning wurde ursprünglich mit dem Untertitel „Herausforderungen und Erfolgsfaktoren der OZG-Umsetzung in der Kommunalverwaltung“" publiziert. Der Autor hat jedoch nachträglich darum gebeten, den Beitragstitel dahingehend zu korrigieren, dass der Beitragstitel im Ganzen wie folgt lautet:

Digitalisierung öffentlicher Dienstleistungen: Herausforderungen und Erfolgsfaktoren der OZG-Umsetzung in der Kommunalverwaltung

Der englische Titel soll entsprechend „Digitalization of Public Services: Challenges and Success Factors of the Online Access Act Implementation“ lauten.

Der Originalbeitrag wurde korrigiert.

Die Online-Version des Originalartikels ist unter https://doi.org/10.1365/s40702-021-00765-5 zu finden. 